Cummins, C. S. \& Harris, H. (1956). J. gen. Microbiol. 14, 583-600

\title{
The Chemical Composition of the Cell Wall in some Gram-positive Bacteria and its Possible Value as a Taxonomic Gharacter
}

\author{
By C. S. CUMMINS AND H. HARRIS \\ Departments of Bacteriology and Biochemistry, The London Hospital \\ Medical College, London, E. 1
}

\begin{abstract}
SUMMARY: Hydrolysates of cell-wall preparations of more than 60 strains of corynebacteria, lactobacilli, streptococci, staphylococci and other Gram-positive cocci have been examined by paper chromatography. A very high proportion of the amino acid moiety of the cell-wall complex could in each case be accounted for in terms of 3 or 4 of the amino acids alanine, glutamic acid, lysine, diaminopimelic acid, aspartic acid and glycine. These were associated with varying combinations of sugars and amino sugars. In general, each bacterial genus appears to have a characteristic pattern of cell-wall components, particularly in regard to the amino acids present. Variations in the relative proportions of the sugars appear to differentiate the individual species within a genus. The possible value of cell-wall composition as a taxonomic character is discussed.
\end{abstract}

It is now well established that the insoluble fraction obtained by centrifuging suspensions of bacteria which have been mechanically disintegrated is largely composed of cell-wall fragments, and a number of workers have reported on chemical analyses of such fractions from several bacterial species (Mitchell \& Moyle, 1951; Holdsworth, 1952; Salton, 1952, 1953). The present investigation was undertaken when it was found that the cell-wall compositions of several species of corynebacteria resembled each other closely, but differed markedly from those of streptococci. This finding, coupled with the anomalous results obtained with a strain of Corynebacterium pyogenes, suggested that a more systematic investigation of species from different bacterial genera might be profitable. The present paper deals with the results obtained so far in a survey of corynebacteria, lactobacilli, streptococci, staphylococci and a number of other Gram-positive cocci.

The general method has been to grow the organisms on a suitable medium, disintegrate the washed suspension by shaking with ballotini in a Mickle disintegrator, and purify the cell-wall (insoluble) fraction by treatment with proteolytic enzymes. These purified preparations were then hydrolysed in acid and the hydrolysates examined by paper chromatography. Some of the results have been briefly reported previously (Cummins \& Harris, 1955).

\section{MATERIALS AND METHODS}

\section{Strains of bacteria}

Strains obtained from the National Collection of Type Culture (NCTC) or from the National Collection of Industrial Bacteria (NCIB) are listed as such, with their numbers. The sources of other strains were as follows: 
Corynebacterium diphtheriae (gravis, mitis and intermedius) from Dr Donald Payne, Public Health Laboratory, Northallerton; C. ulcerans (gelatin-liquefying, starch-fermenting) from Dr W. H. H. Jebb, Public Health Laboratory, Oxford; C. hofmanni, isolated in the Clinical Laboratory, London Hospital, from throat swabs; C.xerosis, isolated in the Clinical Laboratory, London Hospital, from conjunctival swabs; C. renale, obtained from Dr F. C. O. Valentine, London Hospital (originally from Professor R. Lovell, Royal Veterinary College); C. pyogenes, strains Wye 1, 2, 3 from Veterinary Investigation Centre, Wye, Kent (Mr J. D. Paterson); strains 637 and 13081 from Dr Lane Barksdale, N.Y. University. C. haemolyticum strain 53/W/1 was also obtained from Dr Barksdale, and represents the type strain (MacLean, Liebow \& Rosenberg, 1946).

Streptococcus pyogenes (group A). Isolated in the Clinical Laboratory, London Hospital, from a throat swab. Streptococci of other Lancefield's groups were obtained from the National Collection of Type Cultures. Staphylococcus aureus, strains 1, 2 and 3, isolated from nasal swabs, all coagulase-positive; $S$. albus strains 1, 2 and 3, isolated from nasal swabs, all coagulase-negative. 'These strains were picked as 'aureus' or 'albus' on colonial pigmentation, and were later tested for coagulase production. S. citreus: selected from culture of nasal swab as giving typical lemon yellow pigment, coagulase-negative.

Lactobacilli spp. The strain originally examined was obtained from a sample of yoghurt, and purified by plating out on tomato juice agar. It has not been further identified. Subsequent strains were obtained from the National Collection of Industrial Bacteria.

\section{Identification and naming of strains}

In most cases strains of known origin have been used, either from the NCTC or NCIB. These were checked for purity, but not investigated further. Strains of Corynebacterium diphtheriae had been isolated from cases, and had the typical morphology and fermentation reactions. Strains of $C$. hofmanni isolated from throat swabs were accepted as such if they stained evenly with methylene blue except for a central unstained bar, were strongly Gram-positive and failed to ferment glucose, maltose and sucrose. The strains designated C. xerosis were heavily barred diphtheroids, isolated from conjunctival swabs, which fermented glucose and sucrose and gave rather small dry rough colonies. The single strain of $C$. murium was a non-acid fast corynebacterium, isolated from caseating lesions in a mouse.

With two exceptions strains are listed under the names which they bore when received, the exceptions being two strains of lactobacilli. These were originally received as Lactobacillus bulgaricus (NCTC 76) and $L$. bifidus (NCTC 2797), but we were informed by Dr Dorothy Wheater that according to physiological and serological tests (Wheater, 1955 $a, b$; Sharpe, 1955; Briggs, 1953) these should be reclassified as $L$. helveticus (76) and L. fermenti (2797) respectively. With the agreement of the Curator of the National Collection of Type Cultures, Dr Cowan, we have therefore altered the names but retained the NCTC numbers. 


\section{Culture media}

Streptococci, aerococci and strains of Corynebacterium pyogenes were grown on infusion broth to which had been added before sterilization $0 \cdot 1 \%(w / v)$ sodium phosphate $\left(\mathrm{Na}_{2} \mathrm{HPO}_{4}\right)$. To this broth was added before inoculation a sterile glucose + bicarbonate solution $\left(10 \%\right.$ glucose, $\left.10 \% \mathrm{NaHCO}_{3}\right)$ in the proportion of $2 \mathrm{ml}$. to $100 \mathrm{ml}$. broth. In the case of $C$. pyogenes growth was improved by the further addition of $2 \%$ sterile horse serum.

Staphylococci were grown on nutrient agar in Petri dishes, or in $10 \times 8$ in. metal trays with metal lids; but some more slowly growing strains such as Micrococcus conglomeratus were grown in nutrient broth at $28^{\circ}$ in conical flasks to give good aeration.

Lactobacilli were grown in tomato juice broth (Briggs, 1953) in large screwcapped bottles containing 1 l., for $48 \mathrm{hr}$. at $37^{\circ}$. The suspensions so obtained were usually dirty brown in colour, even after washing, but the cell-wall preparations from them were pure white, as with other organisms.

\section{Preparation of cell-wall suspensions}

Bacteria were harvested from solid media by washing off in distilled water, or collected from liquid media by centrifugation. Pathogenic organisms were killed by heating at $60^{\circ}$ for $1 \mathrm{hr}$. or, in the case of relatively heat-resistant species, with formalin $(0.5 \%)$ overnight at room temperature. These precautions were omitted in the case of non-pathogens.

Suspensions were washed twice in distilled water and the bacteria disintegrated with ballotini (Chance no. 12) in a Mickle tissue disintegrator, using $4 \mathrm{~g}$. ballotini and $6 \mathrm{ml}$. bacterial suspension in each cup. Shaking was done at $4^{\circ}$, and the process judged complete when no intact organisms could be seen in smears stained by Gram's method. The rubber stoppers of the cups were protected by cellophan as suggested by Hotchin, Dawson \& Elford (1952).

After shaking, the cups were centrifuged at 1000 r.p.m. for 5-10 min. to break the froth, and the supernatant decanted. The ballotini were washed three times, with a few ml. of distilled water each time, and the washings added to the original supernatant. This was centrifuged at low speed (c. 1000 r.p.m.) for a short time to remove glass beads, and then at 30004000 r.p.m. until the crude cell-wall fraction was deposited. This was washed once in distilled water, resuspended in 0.05 $\mathrm{m}$-phosphate buffer $(\mathrm{pH} \mathrm{7 \cdot 6)}$ and digested with crystalline trypsin and ribonuclease (Armour) at $37^{\circ}$. Both enzymes were used at $0.5 \mathrm{mg} . / \mathrm{ml}$. Digestion was continued for $2-3 \mathrm{hr}$. and a considerable decrease in opacity generally occurred during this period. The mixture was then centrifuged, the deposit washed twice in distilled water, resuspended in $0.02 \mathrm{~N}-\mathrm{HCl}$ with $1 \mathrm{mg}$. crystalline pepsin (Armour)/ml. and digested at $37^{\circ}$ for $18-24 \mathrm{hr}$. After peptic digestion, the material was finally washed several times in distilled water.

If not hydrolysed immediately, the cell-wall preparations were preserved as 
suspensions in distilled water $+0 \cdot 3 \%$ sodium azide. Such preserved material was centrifuged and washed once in distilled water before hydrolysis.

Ideally, each sample should have been checked by electron microscopy before hydrolysis, but this was impossible. However, a few samples chosen at random were so examined, and these showed that the method gave adequately pure material.

\section{Hydrolysis}

The amount of material used for hydrolysis depended to some extent on the size of the sample available, but in general about $50 \mathrm{mg}$. (dry weight) was used, divided so that two-thirds was used for the investigation of sugars, and the remaining one-third for amino acids.

For sugars. Samples were hydrolysed in $2 \mathrm{~N}-\mathrm{H}_{2} \mathrm{SO}_{4}$ in sealed tubes in a water bath at $100^{\circ}$ for $2 \mathrm{hr}$. After cooling, the hydrolysates were filtered, neutralized with solid $\mathrm{Ba}(\mathrm{OH})_{2}$ and centrifuged, and the supernatant evaporated to dryness in vacuo over $\mathrm{P}_{2} \mathrm{O}_{5}$. The final product was redissolved in $\mathbf{0} \cdot \mathbf{2 - 0} \cdot \mathbf{2 5} \mathrm{ml}$. distilled water.

For amino acids and hexosamines. Samples were hydrolysed in $6 \mathrm{~N}-\mathrm{HCl}$ in sealed tubes at $100^{\circ}$ for $8 \mathrm{hr}$., or in some cases at $105^{\circ}$ for $18-24 \mathrm{hr}$. They were then filtered, evaporated to dryness on a boiling water bath, and finally redissolved in $\mathbf{0} \cdot \mathbf{2}-\mathbf{0} \cdot \mathbf{2 5} \mathrm{ml}$. distilled water.

Various degrees of humin formation were encountered with cell-wall preparations from different organisms. It was most marked in the case of corynebacteria. The humin was filtered off before evaporation on the water bath.

\section{Chromatography}

Amino acids and amino sugars. In all cases two-dimensional descending chromatograms $\left(22 \times 18 \frac{1}{2}\right.$ in. Whatman no. 4 filter-paper $)$ were prepared. Phenol + water $(80: 20)$ in an ammonical atmosphere were used for the first solvent, and lutidine + water $(65: 35)$ for the second. The amount of cell-wall hydrolysate chromatographed in each instance corresponded to about $5 \mathrm{mg}$. dry weight of whole organisms. The spots were revealed by dipping the chromatogram rapidly through a solution of $0.2 \%$ ninhydrin in $95 \%$ acetone and $5 \%$ water, and after it had dried heating at $105^{\circ}$ for $5 \mathrm{~min}$. In general, the amino acids present could be readily identified from the position and colour of the spots obtained. Where there was any uncertainty appropriate markers were added to the hydrolysate. Further confirmation of the identity of the spots was also obtained in certain instances by ionophoresis in buffers at different $\mathrm{pH}$ values. The Elson and Morgan reaction and the reaction with ammonical silver nitrate (Partridge \& Westall, 1948) were also used to differentiate the amino sugars from the amino acids and to confirm the identification of glucosamine and galactosamine.

In most cases after $8 \mathrm{hr}$. hydrolysis in $6 \mathrm{~N}-\mathrm{HCl}$ the only ninhydrin reacting spots present corresponded to known amino acids and amino sugars, and the hydrolysis was therefore regarded as complete. There were, however, two exceptions to this. First, in cell-wall preparations from all the lactobacilli 
examined. With the exception of the various strains of Lactobacillus plantarum, hydrolysis in $6 \mathrm{~N}-\mathrm{HCl}$ for $8 \mathrm{hr}$. revealed strong spots corresponding to aspartic acid, glutamic acid, alanine and lysine, and also a strong unknown spot with $\boldsymbol{R}_{f}$ values about the same as lysine in phenol $+\mathrm{NH}_{3}$ and as glycine in lutidine. On further hydrolysis up to $24 \mathrm{hr}$. this spot gradually became weaker till it disappeared almost entirely. Pari passu there occurred a progressive intensification of the spots corresponding to aspartic acid and lysine, and possibly a less pronounced increase in the glutamic acid and alanine spots. The unknown material was therefore regarded as a peptide relatively resistant to hydrolysis, and probably composed largely of aspartic acid and lysine. No further investigation of this point has yet been undertaken, but for the purposes of the present paper, hydrolysis of the cell-wall preparations in this group of organisms was regarded as complete after $24 \mathrm{hr}$. in $6 \mathrm{~N}-\mathrm{HCl}$ at $105^{\circ}$. Secondly, in all the cell-wall preparations examined there was found a ninhydrin reacting substance, moving in phenol $+\mathrm{NH}_{3}$ somewhat more slowly than either glucosamine or galactosamine, and in lutidine at about the same rate as these amino sugars. In lutidine, and to a lesser extent in phenol $+\mathrm{NH}_{3}$, its $R_{f}$ value was somewhat variable from run to run. The colour after development with ninhydrin was much the same as that given by glucosamine, and it was found to react with the Elson and Morgan reagents and with ammonical silver nitrate in the same way as glucosamine and galactosamine. It did not correspond in chromatographic behaviour or in reactions to any known naturally occurring amino acid or amino sugar. Prolongation of the hydrolysis up to $\mathbf{2 4} \mathrm{hr}$. indicated that it was about as stable as glucosamine and galactosamine under these conditions, and it did not appear to be disrupted into any additional ninhydrinreacting substances. This material seems to correspond closely in properties to the unidentified hexosamine reported by Strange \& Powell (1954) in a soluble peptide obtained from cultures of germinating spores of Bacillus subtilis, $B$. cereus and $B$. megaterium. In the rest of this paper the material will be referred to as "unknown "hexosamine",

Sugars. Adequate resolution of the complex mixtures of sugars encountered in many of these cell-wall hydrolysates could not be obtained by unidimensional chromatography. As a routine, therefore, two-dimensional chromatograms $\left(22 \times 18 \frac{1}{2}\right.$ in., no. 4 Whatman filter-paper $)$ were prepared using phenol + water as the first solvent and lutidine + water as the second. The spots were revealed by dipping in a reagent mixture containing: aniline $2.0 \mathrm{ml}$., phthalic acid $3 \cdot 3 \mathrm{~g}$., acetone $95 \mathrm{ml}$., and water $5 \mathrm{ml}$.; followed by heating at $105^{\circ}$ for 5-10 min. In general, an amount of hydrolysate corresponding to about $20 \mathrm{mg}$. dry weight of whole bacteria was used in the preparation of each chromatogram.

The distribution of the sugars on the chromatograms was substantially as described by Partridge \& Westall (1948), who used phenol $+\mathrm{NH}_{3}$ and collidine as their solvents. In our experiments ammonia was omitted from the phenol run because it was found to lead to excessive streaking of the hexose and pentose spots. The only disadvantage of performing the phenol run in neutral and not alkaline conditions was that the amino sugars were poorly resolved. In 
comparison to the other sugars, however, these substances give a very feeble reaction with aniline hydrogen phthalate, and we relied for their identification on the methods described in the previous section. The individual hexoses and pentoses could be readily identified by their relative positions on the paper and their characteristic colour reactions with aniline hydrogen phthalate.

No attempt at accurate quantitative evaluation of the relative proportions of either the amino acids or sugars has been made. The relative amounts of the different substances present in each case have been arbitrarily graded as ,,,++++++ \pm or trace, according to the relative sizes and intensities of the spots obtained.

\section{RESULTS}

For ease of presentation the results have been collected into several tables, each dealing with strains or species which form a related group, even though in some cases their classification is still uncertain. To bring out more clearly the pattern of amino acids, only the major components have been recorded, and the other columns left blank. The only exception to this is in the comparison between Staphylococcus aureus and $S$. albus, where the difference in the amount of serine appears to be significant, although it was present in amounts considerably smaller than were the other four amino acids.

Although dealt with more fully later, two points may be made at the outset. First, that the pattern of amino acid components appears to distinguish larger groups such as genera, while the species within these groups seem to be distinguished by the sugars and amino sugars which their cell walls contain. This is, however, only a broad distinction, and certain genera such as Streptococcus and Corynebacterium have distinguishing cell-wall sugars which are present in all members of the genus. Secondly, attention may be drawn to the distribution of the unusual amino acid $\alpha, \epsilon$-diaminopimelic acid (D.A.P.) originally described by Work (see Work, 1951) in C. diphtheriae. The present results confirm the suggestion of Work \& Dewey (1953) that the presence or absence of this substance may be of taxonomic importance.

\section{Streptococci}

The results detailed in Table 1 show that the 8 strains examined form a homogeneous group, as far as cell-wall composition is concerned, and the distinguishing components appear to be the methylpentose, rhamnose, and the amino acids alanine, glutamic acid and lysine. A point of considerable interest is the difference in cell-wall composition between the two group $\mathbf{D}$ strains, a difference which is of approximately the same degree as that between either of them and, for example, the strain of group F. Salton (1953) has also examined the cell walls of strain. 6782 (group D), and his results agree closely with the present findings, except that he did not detect mannose in hydrolysates of his preparation. Both Salton, and also McCarty $(1952 a, b)$ found that the polysaccharide part of the cell wall of Streptococcus pyogenes (group A) was 
Glycine . . . . . .

Serine . . . . . . .

Diaminopimelic

acid

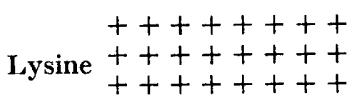$$
++++++
$$

$t++++++$
Glutamic acid $t+++++++$

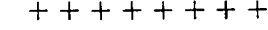

$$
\begin{array}{r}
t+t+t++t \\
\text { Alanine } t++++t+t
\end{array}
$$$$
+t+t+t+
$$

Aspartic acid . . . . . . .

Unknown

'Hexosamine' $++t+++t$

Galactosamine $1 \mathrm{l}_{+}^{+}++1+$

Glucosamine ++++++++

Mannose $|\quad| \quad|+|+\dot{E} \mid 1$



Galactose $1+1+1++$

$t+t++++t$
Rhamnose $t+t++t+t$

Arabinose $1,1,1,1,1 \quad 1$

Serine

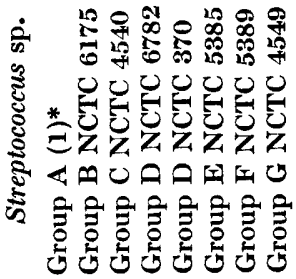

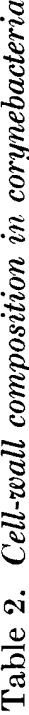

Aspartic acid

Unknown

'Hexosamine' $t+t++t+t+t+t+$

Galactosamine 1 | 1 । $1+t+1+t+t+t+$

Glucosamine $++t+t+t++t+t+t$

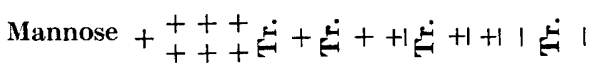$$
\text { Glucose } 1 \text { | }+1++1 \dot{\vec{H}}++_{+}^{+}++++1
$$

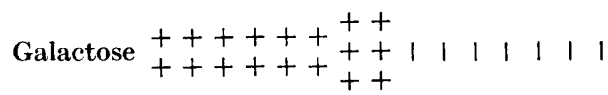

$\begin{array}{lllllllll}\text { Rhamnose } & \mid & \mid & \mid & 1 & \mid & 1 & 1 & +\begin{array}{l}++t+t+t \\ +t+t+t+t\end{array}\end{array}$

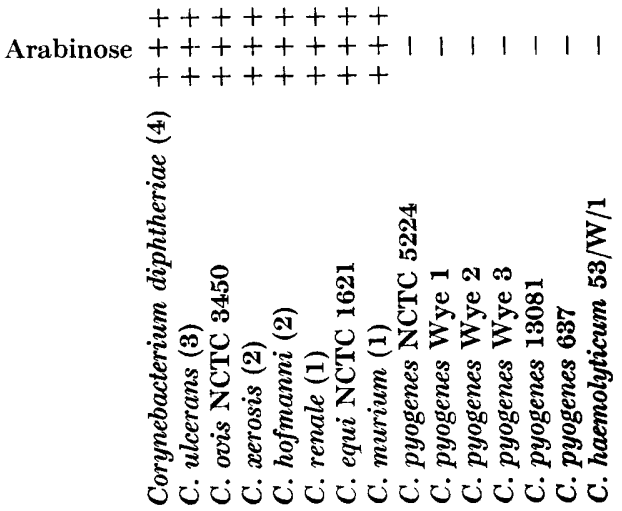


made up of rhamnose and glucosamine, and Salton noted that D.A.P. was absent from the strain of $S$. pyogenes he examined, but that alanine, glutamic acid and lysine were present in larger amounts than other amino acids.

\section{Corynebacteria}

The first eight species in Table 2 (representing fifteen strains) make up a group whose characteristic cell-wall sugars appear to be arabinose and galactose. Although rhamnose was present in the strain of Corynebacterium murium it does not seem to have any more significance in this case than the presence of an approximately equal amount of mannose, when the pattern of components as a whole is considered. The distinguishing amino acids of these eight species are alanine, glutamic acid and D.A.P., which were the major amino acid components in all of them. Diaminopimelic acid has already been identified in hydrolysates of whole $C$. diphtheriae by Work (1951), and Holdsworth (1952) has shown that almost the whole of it is present in the cell-wall fraction of this species. From the same fraction, Holdsworth also obtained an oligosaccharide containing arabinose, galactose and mannose in the ratio $3: 2: 1$, and the results given for $C$. diphtheriae in Table 2 , although only roughly quantitative, agree well with these proportions. The four strains of $C$. diphtheriae examined included two mitis, one intermedius and one gravis strain, but no difference in cell-wall composition was detected between the different cultural types.

The cell-wall compositions of Corynebacterium pyogenes and C. haemolyticum (Table 2) are obviously similar to one another, but differ both in sugar and amino acid composition from the other corynebacteria since they contain neither arabinose nor galactose, and lysine appears as a major component, while D.A.P. is absent. On the other hand, rhamnose was present in both cases, and this, together with the fact that alanine, glutamic acid and lysine were the major amino acid components, suggests very strongly that these organisms are related to the streptococci in view of the results already detailed in Table 1. Six strains of $C$. pyogenes have been examined, and the results are included in Table 2. Taking into account the rather arbitrary method of estimating the amounts of constituents, these six strains showed surprisingly little variation in cell-wall composition, except for the apparently complete absence of mannose in strain 13081. However, this sugar was present only in traces in the cell walls of other strains, and the difference seems hardly significant.

\section{Staphylococci, aerococci, sarcina and micrococci}

The results in Table 3 represent the cell-wall compositions in a number of catalase-positive species of Gram-positive cocci, and several points of interest are evident. First, there is a group in which the major amino acids of the cell wall are alanine, glutamic acid, lysine and glycine, but in which no distinctive sugar appears. This group is represented by the cultures named Staphylococcus aureus, S. albus, S. citreus, Sarcina iutea and Micrococcus luteus (9 strains in all), and within it there seems to be a division between the strains of Staphylococcus 
$\begin{array}{rr}\text { Glycine } & +++t \\ + & ++t+ \\ + & ++t+\end{array}$

Serine $\stackrel{+}{\dot{A}}+\cdot$

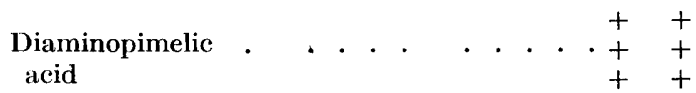

$$
\begin{array}{ccc}
+ & +++t & +++++ \\
\text { Lysine } & ++t+ & +++t+ \\
+ & ++t+ & +++t+
\end{array} .
$$

$\begin{array}{rlrr}+ & ++++ & ++++++ & + \\ \text { Glutamic acid } & ++++ & ++++++ & + \\ + & +++t & +++t++ & +\end{array}$

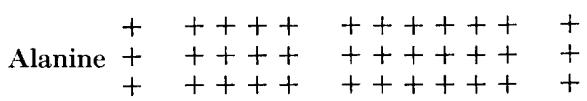

\section{Aspartic acid}

\section{Unknown}

'Hexosamine' ++++++++++

Galactosamine $|\quad| \quad|1| 1 \mid$

Glucosamine +++++++++++

$$
\text { Mannose } 11+111+11 \dot{\oplus \dot{\theta}}
$$$$
\text { Glucose } 1 \quad 1+\begin{gathered}
++ \\
++
\end{gathered}++++1 \quad 1
$$

$$
\begin{array}{llllllllll}
\text { Galactose } & 1 & 1 & 1 & 1 & 1 & + & + & 1 & ++ \\
+ & +
\end{array}
$$



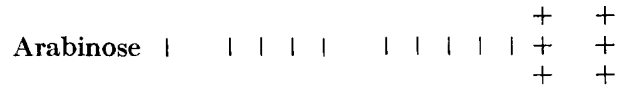

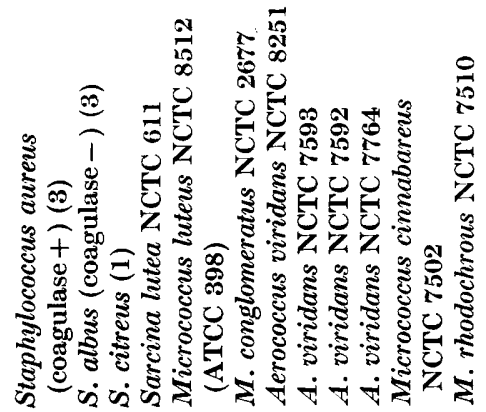


aureus and $S$. albus, which have a moderate amount of serine but no hexoses or pentoses, and the other three strains which contain no serine but have one or more hexoses in the cell wall. There may also be a significant difference between aureus and albus strains in respect of the amount of serine present. Both of these tentative subdivisions require confirmation by the examination of a far larger number of strains.

The second group of strains which can be distinguished among those whose cell-wall compositions are set out in Table 3 are the four strains of Aerococcus and probably also the strain labelled Micrococcus conglomeratus. Williams, Hirch \& Cowan (1953), in defining Aerococcus as a new bacterial genus, described it as being intermediate in many ways between Staphylococcus and Streptococcus. This is borne out by the cell-wall composition of these four strains, the essential pattern of which differs from Streptococcus only in that rhamnose is absent, and from Staphylococcus only in not containing glycine.

Thirdly, there are the two strains labelled Micrococcus rhodochrous and $M$. cinnabareus. These had been rejected on morphological grounds by Shaw, Stitt \& Cowan (1951) and Cowan (personal communication) from their collection of Gram-positive, catalase-positive cocci, and this has been confirmed by us, since both cultures show diphtheroid forms several $\mu$. long, particularly in the case of $\boldsymbol{M}$. cinnabareus. It is interesting to see that by cell-wall composition these two strains would clearly fall into the genus Corynebacterium (Table 2), and the results in each case are so alike as to suggest that they may be two strains of the same species.

\section{Lactobacilli}

The results of cell-wall analyses of 7 strains (the first 7 in Table 4) show that this genus appears to be characterized by aspartic acid, alanine, glutamic acid and lysine as the major amino acids of the cell wall, but has no distinguishing hexose or pentose. The 2 strains of Lactobacillus casei and $L$. delbrueckii have a rather more complicated cell-wall structure than the others; galactosamine as well as glucosamine is present, both strains contain rhamnose, and the strain $L$. case $i$ has also a small amount of arabinose. However, their amino acid pattern is the same as the other 5 strains under discussion, and all 7 seem to form a homogeneous group with the characters mentioned above.

The 4 strains of Lactobacillus plantarum, on the other hand, differ from the other strains of lactobacilli in three ways so far as the amino acid pattern in their cell walls is concerned: they lack aspartic acid and lysine and contain D.A.P. Diaminopimelic acid was found by Work \& Dewey (1953) in the strain of $L$. plantarum which they examined, although they did not identify it as a cell-wall component since they examined hydrolysates of whole organisms.

\section{DISCUSSION}

General nature of the cell wall

The present series of results represents the analyses of cell-wall composition in nearly 60 strains, and is large enough to enable some general conclusions to be drawn as to the nature of the cell wall in Gram-positive bacteria. 


\section{Glycine}

Serine

Diaminopimelic acid

$+++$ ++++
++++

$$
\begin{array}{cc}
t \quad+t+t+t \\
\text { Lysine } \quad+t+t+\ldots \\
+\quad+t+t+t
\end{array}
$$

$\begin{array}{cc}+ & ++++++++++ \\ \text { Glutamic acid } & ++++++++++ \\ + & ++++++++++\end{array}$

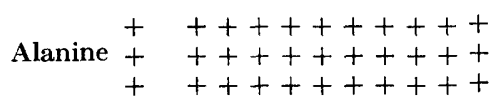

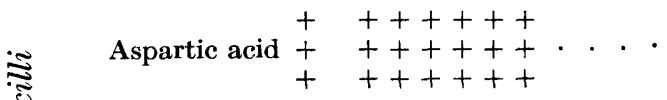

$\begin{aligned} & \text { Unknown } \\ & \text { Hexosamine' }\end{aligned}+++++++++$

Galactosamine $1 \quad 1 \quad 1 \quad 1 \quad 1++1 \quad 1 \quad 1 \quad 1$

Glucosamine $++t+++++t$

Mannose +1 | $1 \dot{\vec{E} \dot{+}+\dot{H}} 1++1$



Galactose $\dot{0} \quad 1 \quad \begin{aligned} & +1++1 \\ & +++1\end{aligned}$

Rhamnose $111111 t_{+}^{+} \begin{array}{llll}1 & 1 & 1 & 1\end{array}$

Arabinose $1 \quad 1 \quad 1 \quad 1 \quad 1 \quad \Leftrightarrow 111$

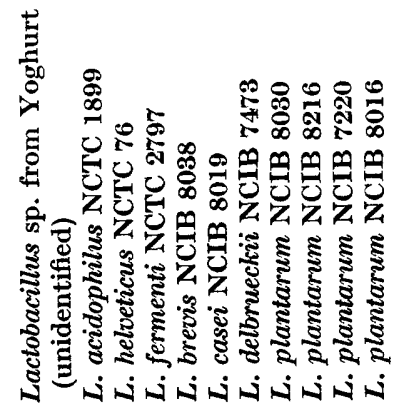


Characteristically the cell-wall material is very tough and extremely insoluble in a wide variety of solvents. It is made up to a large extent of sugar and amino acid components and presumably, therefore, falls into the class of 'mucoids' or ' mucosubstances' (Kent \& Whitehouse, 1955). A similar conclusion was reached by Salton $(1952,1953)$ as a result of his findings in a smaller series of five Gram-positive and two Gram-negative species. One remarkable feature is the apparent simplicity of the amino acid patterns encountered, in contrast to the findings in other mucoids or in proteins.

Sugars and amino sugars were present in every preparation except those from Staphylococcus aureus and $S$. albus, in whose cell walls no hexoses or pentoses were detected, but these can be regarded as limiting cases. Glucosamine was invariably found, as was the unknown hexosamine-like substance already described in the section on methods. The exact nature of this substance is still obscure. Galactosamine, on the other hand, was present in only about one-third of the species examined. Among the sugars one or more of the three hexoses, glucose, galactose and mannose, seemed to be almost invariably present; arabinose and rhamnose occurred less frequently and had a more restricted range. Ribose has not been detected in cell-wall hydrolysates except in the case of some strains of corynebacteria. The amount was usually small and varied considerably in different preparations from the same strain, being entirely absent from some. Holdsworth (1952) did not detect ribose in the cell wall of Corynebacterium diphtheriae, and Salton (1953) did not find it in the wall of any of the seven species of bacteria he examined. It seems most likely, therefore, that the preparations in which ribose was present had not been adequately purified.

A very high proportion of the amino acid moiety of the cell-wall complex could in each case be accounted for in terms of three or four of the following amino acids : alanine, glutamic acid, lysine, $\alpha, \epsilon$-diaminopimelic acid, aspartic acid and glycine. Of these alanine and glutamic acid were invariably present as major components. The others were found to be characteristic major components of the cell walls of some organisms but not of others.

Apart from these major components, other amino acids were encountered in relatively smaller amounts in some of the preparations. We have never had any difficulty in deciding whether to call an amino acid a major or a minor component in any particular case, but the significance of the minor components is rather difficult to assess. They do not seem to be constant from one sample to another, and have generally been present only in traces except in the case of some preparations from corynebacteria examined early in the series, which showed moderately strong spots for lysine, serine, glycine, aspartic acid, valine and the leucines, as well as the characteristic major spots for alanine, glutamic acid and D.A.P. These corynebacterial preparations also contained a variable amount of ribose, and might legitimately be regarded as being contaminated by cytoplasmic remains. In other cases there were frequently no 'traces', for example, in hydrolysates from Staphylococcus aureus and Lactobacillus plantarum. It is not possible to decide at the moment whether these minor amino acid components are part of the cell-wall complex proper, or whether they 
represent the remains of surface protein layers as exemplified by the $\mathbf{M}$ antigens of streptococci, or cytoplasmic remnants in slightly impure cell-wall suspensions.

The individual amino acids found are common ones, except for D.A.P., which has so far been described only in bacteria or their products (Work, 1951, 1955). The distribution of this substance among a variety of micro-organisms including bacteria, fungi, yeasts and protozoa was surveyed by Work \& Dewey (1953), who examined hydrolysates of whole organisms. We have not noted any discrepancies between the distribution of D.A.P. as described by these workers in whole organisms of various species, and our own findings on separated cell walls and it seems possible that the bulk of the D.A.P. in Gram-positive bacteria is situated in the cell wall.

In the species we have examined, the cell walls contain either D.A.P. or lysine as a major component, but not both in similar quantities. This perhaps suggests that they have similar structural functions. Lysine can be formed from D.A.P. by the action of D.A.P. decarboxylase which is fairly widely distributed in bacteria (Dewey, 1954; Work, 1955), and it might have been expected that the decarboxylase would be found in those cases in which lysine and not D.A.P. was a major cell-wall component. There is, however, no such simple relationship, since some organisms which have lysine in their cell walls seem to be devoid of decarboxylase activity, while others which have D.A.P. apparently contain the enzyme (Work, 1955).

No account has been taken here of lipid components which may be present in the cell walls of any of the species examined. It would seem from the findings of Salton (1953) that this type of substance forms at most a relatively small part of the cell wall in Gram-positive bacteria. For example, he found $1 \cdot 2 \%$ total lipid in the cell walls of Micrococcus lysodeikticus, and $2.6 \%$ in those of Bacillus subtilis. In both cases the lipid was firmly bound, and did not seem to be completely liberated until after several hours hydrolysis in $6 \mathrm{~N}-\mathrm{HCl}$ at $100^{\circ}$.

Proteolytic enzymes are without effect on the cell-wall material as a whole, but may remove surface protein components such as the $M$ antigens of streptococci (Salton, 1953). The removal of this material with trypsin made no difference to the appearance of the cell wall in electron micrographs, and did not seem to alter its physical properties, but Salton noted that the amino acid constitution was simpler after treatment with trypsin, and that in particular sulphur-containing and aromatic amino acids were no longer present. Cummins (1954) found that a superficial protein antigen in a strain of Corynebacterium diphtheriae appeared to be destroyed by pepsin, and it was this observation, together with Salton's findings in the case of the $\mathbf{M}$ antigen, that led us to adopt the routine use of trypsin followed by pepsin in the purification of the cell-wall material, in the hope of obtaining as simple a pattern of components as possible.

\section{Cell-wall composition and bacterial taxonomy}

The qualities necessary for a good taxonomic character have recently been discussed in some detail (Report of Discussion Meeting on the Principles of Microbial Classification, 1955), and the chemical composition of the bacterial 
cell wall appears to fulfil in many respects the necessary requirements. The preparation of the purified cell-wall fractions, although somewhat laborious, is not technically difficult, and the components present can be accurately identified, if necessary, by comparison with synthetic standards. Cell-wall composition is also in our experience a stable character, unaffected by variations in culture media or conditions of growth, and this point is underlined by the close agreement between the present results and those of other workers. Our findings in the case of Streptococcus faecalis (NCTC 6782), for example, are virtually identical with those of Salton (1953) with the same strain, and there is the same degree of correspondence in the case of Sarcina lutea, although in this instance different strains were used.

In an attempt to test the stability of cell-wall composition under altered metabolic conditions, a strain of Staphylococcus aureus was 'trained' over a period of several months by growth in gradually increasing concentrations of penicillin in broth. The highly resistant strain so obtained would grow in the presence of 5000 units penicillin/ml., but its cell-wall composition was unaltered when compared with that of the original culture. It should be pointed out, however, that this resistant strain differed from those described by Gale \& Rodwell (1948) and by Bellamy \& Klimek (1948), in that it still retained the coccal form, and was still Gram-positive although somewhat irregularly so; it also grew both aerobically and anaerobically. The resistant strains described by the authors quoted appeared in stained films as pleomorphic Gramnegative bacilli, and would not grow anaerobically. They may therefore have undergone a more fundamental alteration than the strain described in the present paper.

Bacterial taxonomy is at present based on a number of different criteria, of which those of widest application are probably morphological appearances and staining properties, antigenic characteristics, and tests of biochemical activity which reflect various aspects of intermediary metabolism, mainly catabolic. Cell-wall composition can perhaps be regarded as an extension of morphology at the biochemical level; a sort of chemical anatomy. It is probably quite intimately connected with antigenic characteristics, since it is likely that important cell antigens are located in the cell wall, and indeed form a major part of it. It seems quite clear, for example, from the results of McCarty $(1952 a, b)$ and Salton (1953) that the cell walls of Streptococcus pyogenes, as prepared by mechanical disintegration, contain both the $\mathbf{M}$ protein and the $\mathrm{C}$ polysaccharide and since McCarty, and also Schmidt (1952), have shown that the latter is composed of rhamnose and hexosamine, it is not unlikely that it represents the polysaccharide moiety of the basic cell-wall substance in this species.

In the four main groups of Gram-positive bacteria so far examined (streptococci, corynebacteria, staphylococci and lactobacilli), the results of cell-wall analysis agree well with the genera already defined by the use of other taxonomic characters. The differences in composition seem clear cut and easily recognizable, and there would be no difficulty, for example, in distinguishing by this method a staphylococcus from a streptococcus, or a lactobacillus from 
a corynebacterium. Figs. 1 and 2 show, in diagrammatic fashion, the pattern of constituents found in representative species of these four genera.

The general picture that emerges is one in which the amino acids present in the cell wall seem to be characteristic of the genus, and the sugars and amino sugars seem to characterize the species within the genus, with the important exception of arabinose and rhamnose, which appear to have special significance in Corynebacterium and Streptococcus respectively. In most cases only one strain of each species was examined, and the degree of species variation to be expected is not known. Where more than one strain has been analysed, the results have in some cases been virtually identical (e.g. Corynebacterium diphtheriae), while in others there have been definite qualitative differences in the sugar components present (e.g. Lactobacillus plantarum).

If it can be accepted that distinctive patterns of cell-wall constituents characterize different genera, then any organism which differs markedly in cell-wall composition from others in the genus to which it is normally assigned becomes of particular interest. In the present investigation three series of strains have given anomalous results of this sort, and they are considered below in turn.

In the case of Corynebacterium pyogenes and C. haemolyticum the results of cell-wall analysis are at variance with those obtained in other corynebacteria. The findings in the 6 strains of $C$. pyogenes, for example, would support the rejection of this species from the genus Corynebacterium and its inclusion instead in Streptococcus, since it contains rhamnose and not arabinose as a distinguishing cell-wall sugar, and has alanine, glutamic acid and lysine as major amino acid components, but lacks D.A.P. The same arguments apply also to the single strain of $C$. haemolyticum examined. There is no doubt that these organisms would be included with the corynebacteria, if morphology alone were considered, although in some conditions they can be almost coccal. On the other hand, McLean et al. (1946), in their original description of C. haemolyticum, commented on the close resemblance of this species to Streptococcus pyogenes, and the growth of Corynebacterium pyogenes on blood agar and in broth resembles very closely that of a $\beta$-haemolytic streptococcus. In addition, both species resemble the streptococci in being catalase-negative, while other corynebacteria are catalase-positive. It seems to us, therefore, that there are good grounds for reconsidering the taxonomic position of C. pyogenes and C. haemolyticum, with a view to their inclusion in the genus Streptococcus.

The results of cell-wall analysis in the case of the four strains of Lactobacillus plantarum present a more difficult problem. The amino acid pattern in these strains is quite different from that of the other lactobacilli examined, and is in fact identical with the pattern found in Corynebacterium, and with that which a few preliminary observations suggest may also be found in the genus Bacillus (Salton, 1953; Cummins \& Harris, unpublished observations). Quite apart from any morphological and physiological differences, however, these four strains of Lactobacillus plantarum were distinguished from the corynebacteria by the fact that none of them contained arabinose as a major cell-wall component, nor is there any evidence to suggest any close relationship to the 


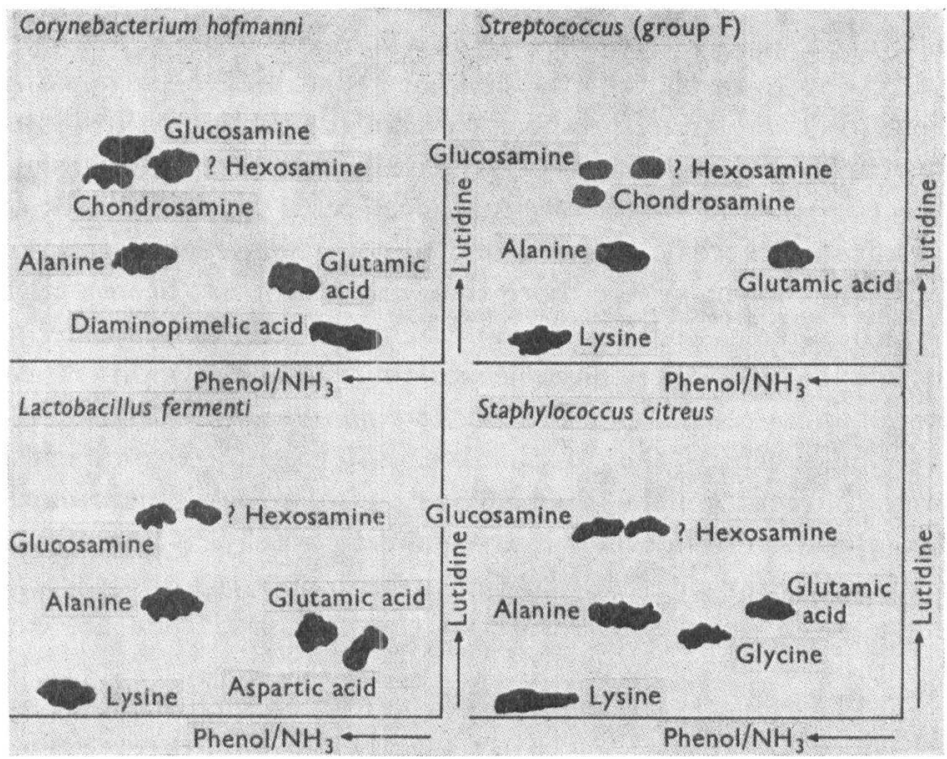

Fig. 1. Diagrams of typical chromatograms showing the amino acid and amino sugar patterns in representative species of four different genera.

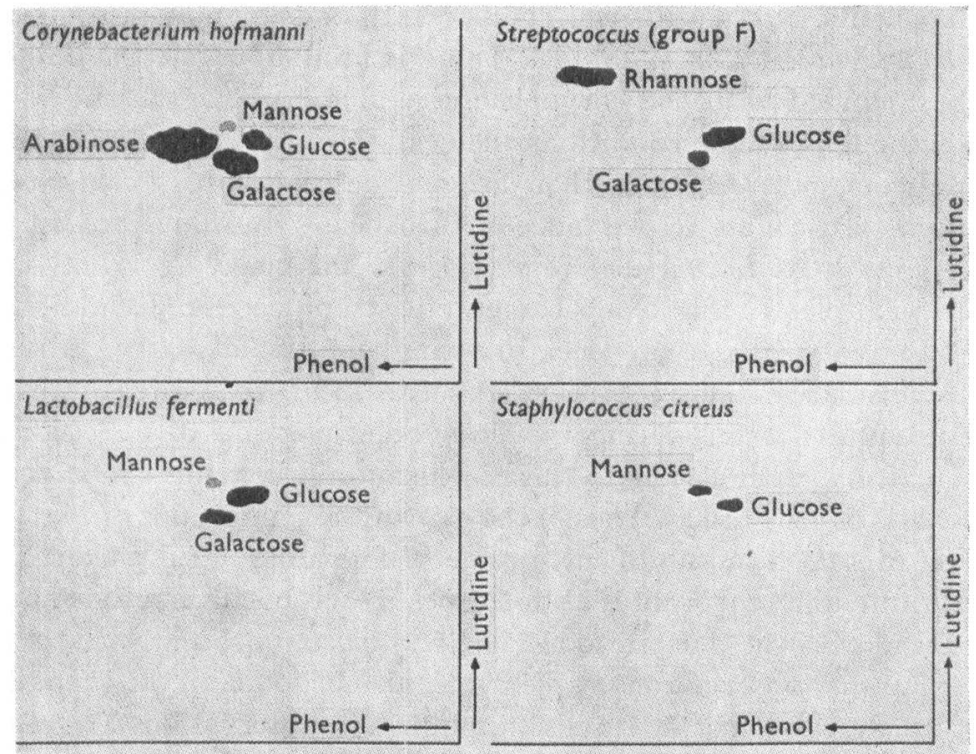

Fig. 2. Diagrams of typical chromatograms showing the sugar patterns in representative species of four different genera. 
aerobic sporing bacilli. More than eighty strains of Lactobacillus plantarum, together with other species of lactobacilli, have recently been investigated by physiological and serological methods (Wheater 1955 $a$, $b$; Briggs 1953; Sharpe, 1955 ), and the results obtained did not suggest that the position of $L$. plantarum in this genus was anomalous (Wheater, personal communication). It is interesting, however, to note that Camien (1952) found D-aspartic acid to be an essential metabolite for $L$. brevis and $L$. lycopersici, while it was not required by a strain of $L$. plantarum. Furthermore, D-aspartic acid could not be detected in hydrolysates of the latter species, although significant amounts of it were found in the other lactobacilli. The significance of the unusual cell-wall composition of $L$. plantarum may become apparent when a wider survey of other Gram-positive bacilli has been undertaken.

With regard to the two strains labelled Micrococcus rhodochrous and M. cinnabareus (Table 3), reasons have already been given for thinking that these organisms belong to the genus Corynebacterium. It seems possible that the same consideration might apply to various other strains at present classified as Rhodococcus.

We are indebted to Professor C. F. Barwell, Professor F. L. Warren and Dr S. T. Cowan for reading the manuscript, and to Dr Cowan also for much helpful advice on points of bacterial taxonomy; to Dr Dorothy Wheater for information about physiological tests in the classification of lactobacilli; to Dr D. Payne, Dr W. H. H. Jebb Dr F. C. O. Valentine, Dr Lane Barksdale and Mr J. D. Paterson for providing cultures for examination; to Mr R. C. Valentine, National Institute for Medical Research, Mill Hill, for electron micrographs; and finally to Mr B. Cohen for his excellent and painstaking technical assistance.

\section{REFERENCES}

Bellamy, W. D. \& Klimek, J. W. (1948). Some properties of penicillin-resistant staphylococci. J. Bact. 55, 153.

BrigGs, M. (1953). The classification of lactobacilli by means of physiological tests. J. gen. Microbiol. 9, 234.

Camien, M. N. (1952). Antagonisms in the utilization of $\mathrm{D}$-amino acids by lactic acid bacteria. IV. D-aspartic acid. J. biol. Chem. 197, 687.

Cummins, C. S. (1954). Some observations on the nature of the antigens in the cell wall of Corynebacterium diphtheriae. Brit. J. exp. Path. 35, 166.

Cummins, C. S. \& Harris, H. (1955). Differences in cell wall composition among Gram-positive cocci and bacilli. J. gen. Microbiol. 13, iii.

Dewey, D. L. (1954). The distribution of diaminopimelic acid decarboxylase among some organisms of the coli-aerogenes group and certain other bacteria. J. gen. Microbiol. 11, 307.

Gale, E. F. \& Rodwell, A. W. (1948). Amino acid metabolism of penicillinresistant staphylococei. J. Bact. 55, 161.

Holdsworth, E. S. (1952). The nature of the cell wall of Corynebacterium diphtheriae. Isolation of an oligosaccharide. Biochim. biophys. Acta, 9, 19.

Hotchin, J. E., Dawson, I. M. \& Elford, W. J. (1952). The use of empty bacterial membranes in the study of the adsorption of Staphylococcus $K$ phage upon its host. Brit. J. exp. Path. 33, 177.

Kent, P. W. \& Whitehouse, M. W. (1955). Biochemistry of the Amino Sugars. London: Butterworth. 
Maclean, P. D., Liebow, A. A. \& Rosenberg, A. A. (1946). A hemolytic corynebacterium resembling Corynebacterium ovis and Corynebacterium pyogenes in man. J. infect. Dis. 79, 69.

MCCARTY, M. (1952a). The lysis of group A hemolytic streptococei by extracellular enzymes of Streptomyces albus. I. Production and fractionation of the lytic enzymes. J. exp. Med. 96, 555.

McCarty, M. (1952b). The lysis of group A hemolytic streptococci by extracellular enzymes of Streptomyces albus. II. Nature of the cellular substrate attacked by the lytic enzymes. J. exp. Med. 96, 569.

Mitchell, P.\& Moyle, J. (1951). The glycerophospho-protein complex envelope of Micrococcus pyogenes. J. gen. Microbiol. 5, 981.

Partridge, S. M. \& Westale, R. G. (1948). Filter paper partition chromatography of sugars. 1. General description and application to the qualitative analysis of sugars in apple-juice, egg-white and foetal blood of sheep. Biochem. J. 42, 238.

Report of Discussion Meeting of the Society for General Microbiology on the Principles of Microbial Classification, September 1954 (1955). J. gen. Microbiol. 12, 314.

Salton, M. R. J. (1952). Studies of the bacterial cell wall. III. Preliminary investigations of the chemical constitution of the cell wall of Streptococcus faecalis. Biochim. biophys. Acta, 8, 510.

Salton, M. R. J. (1953). Studies of the bacterial cell wall. IV. The composition of the cell walls of some Gram positive and Gram negative bacteria. Biochim. biophys. Acta, 10, 512.

Schmid, W. C. (1952). Group A streptococcus polysaccharide: studies on its preparation, chemical composition and cellular localization after intravenous injection into mice. J. exp. Med. 95, 105.

Sharpe, M. E. (1955). A serological classification of lactobacilli. J. gen. Microbiol. $12,107$.

Shaw, C., Stitt, J. \& Cowan, S. 'T. (1951). Staphylococci and their classification. J. gen. Microbiol. 5, 1010.

Strange, R. E. \& Powell, J. F. (1954). Hexosamine-containing peptides in spores of Bacillus subtilis. B. megatherium and B. cereus. Biochem. J. 58, 80.

WheATER, D. M. (1955a). The characteristics of Lactobacillus acidophilus and Lactobacillus bulgaricus. J. gen. Microbiol. 12, 123.

Wheater, D. M. (1955b). The characteristics of Lactobacillus plantarum, L. helveticus and L. casei. J. gen. Microbiol. 12, 133.

Williams, R. E. O., Hirch, A. \& Cowan, S. T. (1953). Aerococcus, a new bacterial genus. J. gen. Microbiol. 8, 475.

Work, E. (1951). The isolation of $\alpha, \epsilon$-diaminopimelic acid from Corynebacterium diphtheriae and Mycobacterium tuberculosis. Biochem. J. 49, 17.

Work, E. (1955). Some comparative aspects of lysine metabolism. In Amino Acid metabolism, p. 462, ed. McElroy \& Glass. Baltimore: Johns Hopkins Press.

Work, E. \& Dewey, D. L. (1953). The distribution of $\alpha, \epsilon$-diaminopimelic acid among various micro-organismis. J. gen. Microbiol. 9, 394. 